\title{
Impact of interpersonal conflict in health care setting on patient care; the role of nursing leadership style on resolving the conflict
}

\begin{abstract}
An interpersonal conflict is a disagreement between two persons or subgroups of an organization involving significant bitterness and dissatisfaction. Health care professionals, who understand each other's roles and can work effectively together, have been shown to provide higher quality care and hence, to achieve desire out comes in patient care, it is essential to have good interpersonal relationship in terms of cooperation, collaboration, listen, and respect the values or positions of each other. Strong and effective leadership styles are key components to any health care success. There are certain situations which demand different leadership approaches. Historian and Burns in 1978 developed transformational leadership theory, which emphasizes the importance of interpersonal relationship. Conflict management is a complex process, which demands time and energy. The management and the subordinates must be concerned and devoted to resolving conflict among coworkers by being willing to listen and to find accurate solutions. To overcome interpersonal conflict in the health care setting requires accurate knowledge and skills for health care professionals to reduce the occurrence of conflict. This paper has implications for nurse leaders and organizations who seek to manage conflict among employees to reduce its negative consequences on working environment and organization productivity.
\end{abstract}

Keywords: conflict, interpersonal conflict, health care setting, job satisfaction, nurses
Volume 2 Issue 2 - 2017

\section{Muslim Shah}

Department of Nursing, Rehman College of Nursing, Pakistan

Correspondence: Muslim Shah, Department of Nursing, Rehman College of Nursing, Pakistan,

Email muslimshah266@gmail.com

Received: December 06, 2016 | Published: January 31, 2017

\section{Introduction}

An interpersonal conflict is a disagreement between two persons or subgroups of an organization involving significant bitterness and dissatisfaction. ${ }^{1}$ Interpersonal conflict usually develops due to altered interpersonal relationship among coworkers or unequal distribution of tasks or lack of understanding of situation by employees. Relationship means being connected or related positively. So relationship plays significant role in causing, and resolution of conflict in effective way. According to Martin et al. ${ }^{2}$ that relationships are a main source of pleasure and provide defense against stress and because of good relationships, individuals receive active help for difficult tasks and challenges in jobs, emotional support in their daily lives, and companionship in shared activities. On the other hand, if there is no relationship or misunderstanding, obviously conflict will arise and outcome would be distress and ineffective working environment. Recently health care organizations have become complex due to recruitment, lack of resources, communication skills, and work overload. These are subjected to complex interpersonal dynamics among colleagues, and if policies are exist to identify and resolve these, then out come in terms of job satisfaction by employees, and patient satisfaction through standard care will be improved. The Center for American Nurses conducted a survey in 2009, to recognize challenges related to conflict encountered by the professional registered nurse, that interpersonal conflict is the most frequent and problematic type of conflict experiencing in work place. ${ }^{3}$ No one denies this fact but usually the manager pays less attention due to busy schedule and adopts avoidance style which result in poor work related attitudes and psychological states, such as job dissatisfaction, organizational commitment, turnover intensions, negative emotions, and emotional exhaustion. Hence, it is important for the nurse leaders to identify the source of conflict which may terrible impact on patient care, and to manage conflict by understanding the strategies for the effectiveness of health care setting.

\section{Significance of the issue}

Johansen $^{3}$ reports that workplace conflicts in the healthcare environment tend to be far more complicated because they often involve ongoing, complex relationships that are based in emotion. As in hospital one would interact with different human resources with diversity, including physicians, nurses, managers and personnel's from same or other departments. However, some time nurses are working under difficult and stressful situation which can lead to negative interpersonal relationship with other co-workers, and they are so busy in their work to reflect upon and to resolve it. As a result, patient care will be compromised and organization would lose its productivity. Health care professionals, who understand each other's roles and can work effectively together, have been shown to provide higher quality care. ${ }^{4}$ Hence, to achieve desire out comes in patient care, it is essential to have good interpersonal relationship in terms of cooperation, collaboration, listen, and respect the values or positions of each other. It is usually observed in our context that physicians showing dominancy and lack of acceptance of role of nurses are the root causes of interpersonal conflict in health care settings.

There are number of researches on conflict in health care, especially regarding nurses issues in clinical areas. The most important sources of conflict are deviating management style, staff perceptions, and scarce resources in the unit resulting in higher levels of stress, differences in goals among work groups and competition. ${ }^{5}$ Hence, managerial style 
plays a vital role when conflict is arising either within group or with manager. However, stressful environment, difficulty in achieving the goal and misperceptions lead to conflict. In this regard lack of job satisfaction and staff turnover will result low work outcome and have direct effect on patient care and professional image. There are many skills, those we should learn and practice to work together in a specific way, which may acceptable to all. These skills are not inherent but we can learn through education and ongoing experiences. Grady ${ }^{6}$ argued that managers come across such conflicts which arise from these skills deficiencies more than any other reasons. The nurses usually when enter the patient care setting; they have fewer opportunities to get formal training regarding such skills. Conflict is the root cause for any mishap in patient care, these are medication error, improper communication, lack of respect, delay care, cultural and religious valves violation, which would have a direct impact on image of organization, as a result staff turnover and job dissatisfaction will be escalated. So it is essential for a nurse leader to identify the causes and sources of conflict, for which the leader should have specific skills to avoid it and improve the quality of patient care.

\section{Strategies to resolve interpersonal conflict}

Today health care settings face more challenges as compare to past decades because of competition, downsizing, restructuring, cost control and new technology; these changes are likely to develop conflict in organization. There are many strategies to resolve conflict effectively to minimize its negative impacts. Organization and organizational leaders typically play a role in resolving conflict among the employees. Romer et al. ${ }^{1}$ proposed a research model of "Leaders' Third-Party Conflict Management Behaviors" which is neutral and resolving the conflict in three ways, which are problem solving, forcing, and avoiding. Problem solving is to identify the concerns of both parties and to find a suitable solution which addresses their concerns. Forcing is the imposing of decision by leader to resolve the conflict. Avoiding is the strategy when the leader does not want to involve in the conflict. These three components are suggested to resolve interpersonal conflict among coworkers. Problem solving behavior allowing the individuals to show their goals and point of view, they take it positively as the leader showing interest in their concerns. Hence, when the employees perceive their importance; so, their feelings of controlling the stressful situation enhance, and therefore, negative impact of conflict decreases. This indicates participatory leadership style in which employees are given the opportunity to participate in the decision making process, which minimizing feeling of stress. According to Maboko ${ }^{7}$ involving subordinates in resolving the problems leads to team spirit, which produces job satisfaction, cost effectiveness and better solutions. Furthermore, if there is conflict, the authorized leader should ensure that it is fruitfully resolved. In contrast, forcing behavior has negative impact on employee but based on leader's interest, and would increase stress rather than resolve the conflict in healthy way. However, conflict may be resolved to some extent as the employees expected the leader to be authoritative and obliged to obey. Furthermore, avoiding behavior may cause frustration in the employees because the leader fails to resolve the conflict and thus conflict will be escalated. Avoiding strategy is better but if the employees perceive it positively, otherwise as in the scenario the situation was worsened.

\section{Conceptual framework}

Nurses do not have enough time for research and analysis specified for formalizing processes through scientific method, so many problems need immediate action to find the solution. Sullivan et al. ${ }^{8}$ developed seven-step process (Appendix A), practical strategy to resolve a problem or conflict, which are the most beneficial steps for nurse leader to be more effective in difficult situations. The first step is to identify the problem, the most important part for a leader to resolution of an interpersonal conflict. The problems should be in descriptive statement rather than judgmental or conclusive, and premature interpretations must be avoided by using thorough inquiry of issues as in the scenario, so that to avoid further mishaps. Accurate assessment of conflict among the coworkers needs to achieve long term goals rather than to just a stopgap measure. After the leader reaches to the root of the problem, then he/she should generate possible solutions. This step will give opportunity to a leader to develop more accurate solutions in regard to specific situations. The leaders once set the solutions; then evaluate the suggested solutions by keeping the subordinates and crisis in mind. Choose the best solution to resolve the issues, which is feasible, satisfactory and acceptable by subordinates and higher management. Now it is the time to implement the solution after a detail plan and practical in term of time consuming and effective. More often the employees usually cooperate with such solution which fit into their favor, while few resist. Then the nurse leader should initiate step to educate the staff to comply with the solution. In this situation participative management style is more perfect, which help to identify acceptable solutions to problems. If problem resolved among the co-workers, keep the problem solving process on continue basis. If the leader evaluates the outcome to ensure that conflict has been resolved and build on that experience, it becomes an expert skill that he/she can use throughout the career. The final step of the process depend upon the succession or failure of the resolving the problem, which if conflict does not resolve then repeat the process.

\section{Leadership style}

Strong and effective leadership styles are key components to any health care success. There are certain situations which demand different leadership approaches. Historian and Burns in 1978 developed transformational leadership theory, which emphasizes the importance of interpersonal relationship. ${ }^{9}$ This theory covers Maslow's higher level of needs which promote self-esteem and elevate self-actualization in terms of achievement, respect, confidence, creativity, problem solving and acceptance. Leaders need to develop a vision, create strategies to overcome conflicts, and to accomplish the changes required to reach the vision. Nurse leaders often face challenges when motivating the staff to function beyond self-interest. A thorough knowledge and skills required if the subordinates refuse to participate. Tomey ${ }^{10}$ defines the need of knowledge for effective leadership while moving in the direction of transformational leadership style is: Knowing oneself, knowing the job, knowing the organization, knowing the business, and knowing the world. Furthermore, Ellis et al. ${ }^{11}$ argue that "effectively implementation of transformational leadership result in agreements about priorities, shared valves, perceived common goals and meaningful purposes". So, one can see that it would be the most effective and desirable in a health care environment. Moreover, transformational leaders' regular highlighting on team goalsis likely to bring about appropriate use of rewards for cooperative behaviors. When confronting disagreement, team members are motivated to consider and incorporate opposing views of co-workers and integrate the most reliable information and the best ideas. ${ }^{12}$ 
If we review all leadership theories, there is no one best leadership style to adopt. ${ }^{13}$ One cannot say that leaders are totally people or task oriented. Leadership effectiveness is influenced by leader, followers and situation, leaders should be aware of their own behaviors and influence on followers, individual differences, group characteristics, motivation, task and situational variables. ${ }^{10}$ Leaders may adjust their style according to the situation and require adaptive behaviors. ${ }^{14}$

\section{Recommendations}

Conflict management is a complex process, which demands time and energy. ${ }^{15}$ The management and the subordinates must be concerned and devoted to resolving conflict among coworkers by being willing to listen and to find accurate solutions. ${ }^{8}$ The following are some useful strategies for management to avoid problematic working environment and to resolve interpersonal conflict in effective way. ${ }^{16}$

These are helpful strategies for mediating interpersonal conflict for nurse leaders, which are as:

a. Be a role model.

b. Be helpful of each individual's needs within the group.

c. Do not hold responsible anyone for the problem.

d. Focus on the issues, not the personalities.

e. Maintaining privacy and confidentiality

f. Exploration of alternatives

g. Give equal time to each party.

h. Select a mutually agreeable solution and develop a plan.

i. Summarize key points and plans.

j. Follow up the plans and give positive feedback to participants.

k. Facilitate further problem solving as necessary.

It is important for individuals to maintain a healthy working environment and avoid stressful situation by respecting the coworkers' values, beliefs, good communication skills, and have enough knowledge to work in a multicultural organization. ${ }^{17}$

\section{Conclusion}

Conflict is inevitable in nature. It is a significant issue within health care organizations all over the world. To overcome interpersonal conflict in the health care setting requires accurate knowledge and skills for health care professionals to reduce the occurrence of conflict. This paper has implications for nurse leaders and organizations who seek to manage conflict among employees to reduce its negative consequences on working environment and organization productivity. Learning to manage conflict may help nurses feel more job satisfaction and obviously have positive impacts on patient care. In addition, nurses are more concerns how they are treated. If they are treated with respect and dignity by colleagues, manager and are working with positive relationship and morale, they will experience a positive working environment with less conflict.

\section{Acknowledgements}

None.

\section{Conflict of interest}

The authors declare no conflict of interest.

\section{References}

1. Römer M, Rispens S, Giebels E, et al. A Helping hand? The moderating role of leaders' Conflict management behavior on the conflict-stress relationship of employees. Negotiation Journal. 2012;28(3):253-277.

2. Martin AJ, Dowson M. Interpersonal relationships, motivation, engagement, and achievement: Yields for theory, Current issues, and educational practice. Review of Educational Research. 2009;79(1):327365 .

3. Johansen ML. Keeping the peace: Conflict management strategies for nurse managers. Nursing Management. 2012;43(2):50-54

4. Begley CM. Developing inter-professional learning: Tactics, teamwork and talk. Nurse Education Today. 2009;29(3):276-283.

5. Vivar CG A. Putting conflict management into practice: a nursing case study. Journal of Nursing Management. 2006;14(3):201-206.

6. Porter O Grady T. Diffuse potential crises with unshakable communication skills. Nursing Management. 2003;34(10):40-42.

7. Maboko DR. Nursing leadership in an academic hospital in Gauteng. Journal of Nursing Management. 2011;20(7):912-920.

8. Sullivan EJ, Decker PJ. Handling conflict: Effective Leadership and Management in nursing. 5th ed. New Jersey, USA: Prentice Hall; 2001.

9. Johnson K, Johnson C, Nicholson D, et al. Make an impact with transformational leadership and shared governance. Nursing Management. 2012;43(10):12-17.

10. Tomey AM. Nursing Management and Leadership. 7th ed. USA: Mosby; 2004.

11. Ellis JR, Hartley CL. Nursing in Today's World: Trends, Issues, and Management. 10th ed. USA: Lippincott Williams, Wilkins; 2012.

12. Zhang X, Cao Q, Tjosvold D. Linking transformational leadership and team performance: a conflict management approach. Journal of Management Studies. 2011;48:1586-1608.

13. Almost J, Doran DM, Hall LM, et al. Antecedents and consequences of intra-group conflict among nurses. Journal of Nursing Management. 2010;18(8):981-992.

14. Dana D. Workplace Conflict Statistics; 2005.

15. Guidroz AM, Wang M, Perez LM. Developing a model of source-specific interpersonal conflict in health care. Stress Health. 2011;28(1):69-79.

16. Kaitelidou D, Kontogianni A, Galanis P, et al. Conflict management and job satisfaction in pediatric hospitals in Greece. Journal of Nursing Management. 2012;20(4):571-578

17. Reddin B. Situation Analysis Management-3D Theory; 2010. 